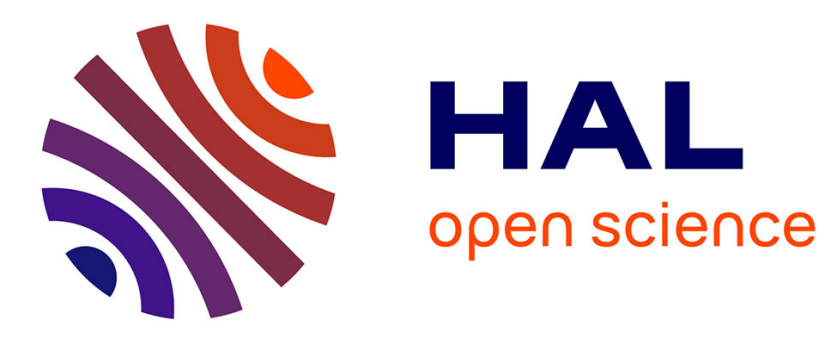

\title{
The Soil Moisture and Ocean Salinity mission: the science objectives of an $\mathrm{L}$ band 2-D interferometer
}

Yann H. Kerr, Philippe Waldteufel, Jean-Pierre Wigneron, Jordi Font

\section{To cite this version:}

Yann H. Kerr, Philippe Waldteufel, Jean-Pierre Wigneron, Jordi Font. The Soil Moisture and Ocean Salinity mission: the science objectives of an L band 2-D interferometer. IGARSS 2000. IEEE 2000 International Geoscience and Remote Sensing Symposium. Taking the Pulse of the Planet: The Role of Remote Sensing in Managing the Environment, Jul 2000, Honolulu, United States. pp.2969-2971, 10.1109/IGARSS.2000.860305 . hal-01655305

\section{HAL Id: hal-01655305 https://hal.science/hal-01655305}

Submitted on 14 Aug 2020

HAL is a multi-disciplinary open access archive for the deposit and dissemination of scientific research documents, whether they are published or not. The documents may come from teaching and research institutions in France or abroad, or from public or private research centers.
L'archive ouverte pluridisciplinaire HAL, est destinée au dépôt et à la diffusion de documents scientifiques de niveau recherche, publiés ou non, émanant des établissements d'enseignement et de recherche français ou étrangers, des laboratoires publics ou privés. 


\title{
The Soil Moisture and Ocean Salinity Mission: The Science Objectives of an L Band 2-D Interferometer
}

\author{
Y.H. KERR (1), P. WALDTEUFEL ${ }^{(2)}$, J.-P. WIGNERON ${ }^{(3)}$ J. FONT $^{(4)}$ \\ ' CESBIO, BPI 2801, 18 av E. Belin, 31401 Toulouse cedex 4, France \\ tel:(33)561558522; fax: (33)561558500;email: yann.kerr@cesbio.cnes.fr \\ ${ }^{2}$ IPSL , 10-12 av de l'Europe, 78140 Vélizy, France \\ ${ }^{3}$ INRA Bioclimatologie, Agroparc 84914 Avignon Cedex 9, France \\ ${ }^{4}$ Institut de Ciencies del Mar C.S.I.C., P. Joan de Borbo s/n, 08039 Barcelona, Spain
}

\section{INTRODUCTION: MISSION RATIONALE}

The main objective of the Soil Moisture and Ocean Salinity (SMOS) mission is to deliver crucial variables of the land surfaces: soil moisture, and of ocean surfaces: sea surface salinity fields. The mission should also deliver information on root zone soil moisture, vegetation, and biomass, and lead to significant research in the field of the cryosphere. The main aspects of the baseline mission are presented in this paper.

Over land, water and energy fluxes at the surface/ atmosphere interface are strongly dependent upon Soil Moisture (SM). Evaporation, infiltration and runoff are driven by $\mathrm{SM}$ while soil moisture in the vadose zone governs the rate of water uptake by vegetation. Soil moisture is thus a key variable in the hydrologic cycle. Soil moisture, and its spatiotemporal evolution as such, is an important variable for numerical weather and climate models, and should be accounted for in hydrology and vegetation monitoring.

For the oceans, Sea Surface Salinity (SSS) plays an important role in the Northern Atlantic sub polar area, where intrusions with a low salinity influence the deep thermohaline circulation and the meridional heat transport. Variations in salinity also influence the near-surface dynamics of tropical oceans, where rainfall modifies the buoyancy of the surface layer and the tropical ocean-atmosphere heat fluxes. SSS fields and their seasonal and inter-annual variabilities are thus tracers and constraints on the water cycle and on the coupled ocean-atmosphere models.

Even though both SM and SSS are used in predictive atmospheric, oceanographic, and hydrologic models, no capability exists to date to measure directly and globally these key variables. The SMOS mission is aimed at filling this gap through the implementation of a satellite that has the potential to provide globally, frequently, and routinely this information. It is also expected that the SMOS mission will provide significant information on vegetation water content, which will be very useful for regional estimates of crop production. Finally, significant research progresses are expected over the cryosphere, through improving the assessment of the snow mantle, and of the multi-layered ice structure. These quantities are of significant importance to the global change issue. Research on sea ice will also be carried out.
The reason why such information are not available currently mainly stems from the fact that, while in situ measurements are very far from global, no dedicated, long term, space mission has been attempted so far.

The only direct way to access to SM and SSS is through the use of $\mathrm{L}$ band $(21 \mathrm{~cm}, 1.4 \mathrm{GHz})$ microwave radiometer systems. Other means (higher frequency radiometry, optical domain, active remote sensing) suffer strong deficiencies, due to vulnerability to cloud cover and/or various perturbing factors (such as soil surface roughness or vegetation cover), as well as poor sensitivity.

Recent development of the so-called interferometry design, inspired from the very large baseline antenna concept (radio astronomy), makes such a venture possible. The idea consists of deploying small receivers in space (located on a deployable structure), then reconstructing a brightness temperature $\left(T_{B}\right)$ field with a resolution corresponding to the spacing between the outmost receivers. The idea was put forward by D. LeVine et al., in the ' 80 's (the ESTAR project) and validated with an airborne system. In Europe, an improved concept was next proposed to ESA. While MIRAS (Microwave Imaging Radiometer using Aperture Synthesis) capitalises on the ESTAR design, it embodies major improvements. The twodimensional MIRAS interferometer allows measuring $T_{B}$ at large incidences, for two polarisations. Moreover, the instrument records instantaneously a whole scene; as the satellite moves, a given point within the 2D field of view is observed from different view angles. One then obtains a series of independent measurements, which allows retrieving surface parameters with much improved accuracy [1].

\section{SCIENCE OBJECTIVES}

\subsection{Land surfaces}

The key variable to monitor over land surfaces for satisfying the above-mentioned goals is surface soil moisture. The main requirement is a sufficient accuracy to make it useful in hydrologic and meteorological models $\left(0.04 \mathrm{~m}^{3} / \mathrm{m}^{3}\right)$ [1], coupled with an adequate temporal sampling. Recent studies [2], have shown that with a revisit of 2 to 4 days depending upon the region was appropriate. The spatial resolution 
requirements are linked to the field of application, i.e., from $100 \mathrm{~km}$ for climate models (Global Circulation Models) to 20 $\mathrm{km}$ or less for hydrology and agronomy. The coverage should be global.

To achieve these goals, it is necessary to account for vegetation contribution and correct for topographic effects and surface temperature. The SMOS concept by delivering angular information allows retrieving soil moisture in presence of vegetation [3]. The vegetation water content is retrieved together with soil moisture in the centre part of the field of view (FOV) every 6 days at most (depending on latitude) and used for soil moisture retrievals in the outer part of the FOV subsequent orbits. Surface topography is constant with time and, once known, can be accounted for. Further studies are required to assess the exact contribution of topography on the signal. Obviously variable footprint size with incidence angle will have to be accounted for. Surface temperature could be retrieved from the angular measurements but with a poor accuracy. However Wigneron et al. [1], have shown that if surface temperature is known with an accuracy of $2 \mathrm{~K}$, The retrieval algorithm would be sufficiently accurate to meet the science objectives. Consequently, classical means of obtaining surface temperature (thermal infra red instruments coupled with models for cloud covered periods, or higher frequency microwave measurements) would be adequate.

Once surface moisture is known, it is possible to infer root zone moisture. Recent studies [4], showed that such data, obtained through microwave radiometry during a continuous hydrological event (e.g. drying period), provide estimates of the corresponding surface hydraulic conductivity value. A similar approach was used in [3], where soil moisture content at field capacity was assessed from in situ measurements of $\mathbf{w}_{s}$.

\subsection{Oceans}

Ocean salinity is a key parameter in determining the ocean circulation and in understanding the water cycle. It is also an important circulation tracer for water masses. Unlike other oceanographic variables, until now, it has not been possible to measure salinity from space. The only means to get consistent estimates of SSS at least at seasonal scales is the use of a satellite-based instrument.

The sensitivity of L-band $(1.4 \mathrm{GHz})$ passive measurements of oceanic brightness temperature $T_{B}$ to SSS is well established [5]. The dielectric constant for seawater depends on both SSS and SST [6]. So, in principle, it is possible to obtain SSS information from L-band passive microwave measurements if the other factors influencing $T_{B}$ can be accounted for. Then the sensitivity of $T_{B}$ to SSS is $0.5 \mathrm{~K} / \mathrm{psu}$ for a SST of $20^{\circ} \mathrm{C}$, decreasing to $0.25 \mathrm{~K} / \mathrm{psu}$ for $0^{\circ} \mathrm{C}$ [5].

Since the radiometric sensitivity achievable is of the order of $1 \mathrm{~K}$, it is clear that SSS cannot be recovered to the required accuracy from a single measurement. However, if the errors contributing to the uncertainty in $T_{B}$ are random, the requirement can be met by averaging the SMOS individual measurements in both space and time [5]. Similarly, monthly averages over $100 \mathrm{~km}$ boxes would give data comparable to the standard climatologies, such as Levitus' [7]. Lower accuracy, higher resolution measurements (typically $0.5 \mathrm{psu}$, $50 \mathrm{~km}, 3$ days) provide a mean to monitor moving salinity fronts in various regions of the world: extension of the warm pool in the equatorial Pacific (lpsu/200km), limit between the upwelled waters (of equatorial or coastal origin) and the subtropical waters ( $1 \mathrm{psu}$ in 200 or $300 \mathrm{~km}$ ), confluence of currents ( 1 to 2 psu Brazil-Malvinas), large river plumes (Amazone). With a SSS single retrieval to 1 psu and a spatial resolution around $30 \mathrm{~km}$ the data are useful for enclosed seas with high salinity contrast (e.g. the Baltic).

The averaging procedure requests excellent stability and calibration of the radiometer receiver. Factors that influence $\mathrm{T}_{\mathrm{B}}$ in addition to SSS, and are to be corrected for, include Sea Surface Temperature (SST), surface roughness, foam, sun glint, rain, ionospheric effects and galactic/cosmic background radiation. Estimates for the uncertainties associated with some of these have been made [5]. Use of L-band radiometry for the measurement of SSS from aircraft has been demonstrated. SSS estimates were previously recovered from the Skylab $1.4 \mathrm{GHz}$ radiometer using a combination of modelling and ancillary data on SST and wind speed.

In order to process SMOS data, corrections due to atmospheric, ionospheric and galactic effects have to be applied. SSS retrieval requires knowledge of sea surface temperature and sea roughness. Over land surfaces, knowledge of the temperature is needed. Over ice, higher frequency microwave data are useful.

\section{MISSION DESCRIPTION}

The baseline SMOS payload in the proposal is an $\mathrm{L}$ band $(1.4 \mathrm{GHz})$ 2D interferometric radiometer, $\mathrm{Y}$ shaped, with three arms. The baseline bus is PROTEUS, developed by the CNES and Alcatel.

The orbit altitude was selected to minimise the accessibility delay for a global coverage assuming an altitude within the range $650-800 \mathrm{~km}$ in order to have a good resolution. The local time is selected to minimise the perturbation on $\mathrm{L}$ band signal (air, vegetation and soil temperature almost identical) and making the Faraday effect minimum, leading to a Sunsynchronous 6 am (ascending) orbit. SMOS's nominal operational orbit parameters are Sun-synchronous, $757 \mathrm{~km}$ altitude $(+/-1 \mathrm{~km})$ with time of ascending node at $6 \mathrm{am}+/-15$ min. These characteristics are subject to changes after the phase A studies.

Data acquisition and pre- processing: The tasks for transforming the actual measurements of the instrument into 
the final image are summarised in the generic term "image reconstruction." The innovative design of the proposed SMOS instrument is based on the novel passive imaging capabilities of aperture synthesis devices. In [8] the image acquisition and reconstruction basis are explained. The various experience and the wide background of the group members, has led to the identification of three main classes of issues: error correction, image reconstruction and calibration. The different tools currently available, concerning both the theoretical and technical aspects, will be used in a complementary manner, so as to develop a novel and innovative tool for an end-to-end simulation of a SMOS-type synthesis radiometer. It will offer solutions for operational error correction, image reconstruction and calibration [9] -[11].

Calibration of the sensor will be first made using usual methods for radiometers (hot and cold sources) coupled with a complete modelling of the instrument and novel techniques (phase closure). However it is also planned to have calibration (in terms of brightness temperatures) using vicarious data. This will be done using several "targets" of identified signatures and easy to monitor. Actually the main problem is linked to the spatial resolutions not compatible with classical ground measurements. Currently several targets have been identified.

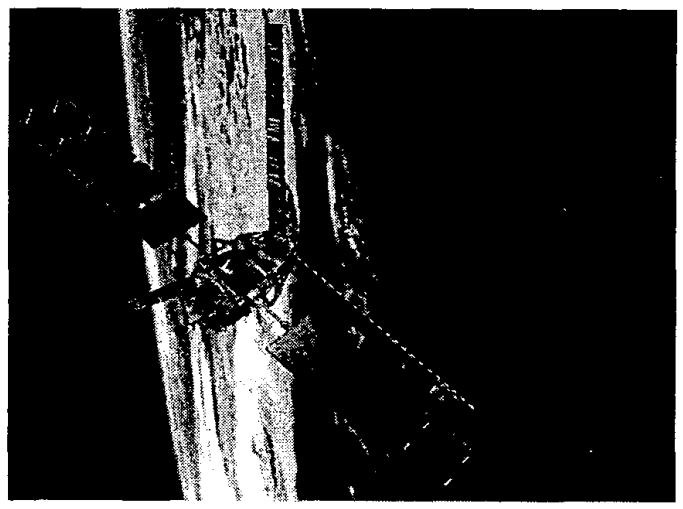

Figure 1: SMOS: Artist's view

\section{CONCLUSION}

The baseline mission described in this paper is ambitious but fully achievable [12]. Actually the novel aspects of the interferometry concept has been validated by the ESTAR concept. The science background is very sound and the mission should fill existing gaps in our knowledge of surface variables (soil moisture, ocean salinity).

The SMOS concept will be a demonstrator of $\mathrm{L}$ band measurements over the globe, paving the way to more ambitious concepts in terms of spatial resolution or frequency range. SMOS will undoubtedly make available long needed measurements of surface soil moisture, vegetation biomass and sea surface salinity and foster new research in these fields as well as in cryospheric studies. SMOS should be launched as a second Earth Explorer Opportunity Mission, tentatively in 2005.

\section{REFERENCES}

[ 1] J.-P. Wigneron, P. Waldteufel, A. Chanzy, J.-C. Calvet, O. Marloie, J.-F. Hanocq and Y. Kerr, "Retrieval capabilities of L-Band 2-D interferometric radiometry over land surfaces (SMOS Mission),VSP in press.

[2] J.-C. Calvet, J. Noilhan and P. Bessemoulin, "Retrieving the root-zone soil moisture from surface soil moisture or temperature estimates: a feasibility study based on field measurements," J. Appl. Meteor., 37, 371-386 (1998).

[3] J.-P. Wigneron, A. Chanzy, J.-C. Calvet and N. Bruguier, "A simple algorithm to retrieve soil moisture and vegetation biomass using passive microwave measurements over crop fields," Remote Sens. Environ., 51, 331-341 (1995).

[4] K. J. Hollenbeck, T. J. Schmugge, G. M. Homberger and J.R. Wang, "Identifying soil hydraulic heterogeneity by detection of: relative change in passive microwave remote sensing observations," Water Resour. Res., 32, 132-148 (1996).

[5] G.S.E. Lagerloef, C.T. Swift and D.M. LeVine, "Sea surface salinity: the next remote sensing challenge," Oceanogr., 8, 44-50 (1995).

[6] L.A. Klein and C.T. Swift, "An improved model for the dielectric constant of sea water at microwave frequencies," IEEE Trans. Ant. Prop., 25, 104-111 (1977):

[7] S. Levitus, R. Burgett and T.P. Boyer, World Ocean Atlas 1994 Volume 3: Salinity, NESDIS 3 (1994).

[8] P. Waldteufel, E. Anterrieu, J. M. Goutoule and Y. Kerr, "Field of view characteristics of a microwave 2-D interferometric antenna, as illustrated by the MIRAS concept,"VSP, in press.

[9] A. Camps, "Application of Interferometric Radiometry to Earth Observation," Ph. D. Dissertation, Universitat Politècnica de Catalunya (1996)

[10] A. Lannes and E. Anterrieu, "Modelization, antenna geometry and algorithms," ESA report on MIRAS, Wps 1220 and 1810 (1994).

[11] A. Lannes, E. Anterrieu and K. Bouyoucef, "Fourier Interpolation and reconstruction via Shannon-type techniques, Part II: Technical developments and applications," J. Mod. Optics, 43, 105-138 (1996).

[12] Y.H. Kerr, et al. "MIRAS on RAMSES: radiometry applied to soil moisture and salinity measurements," Full proposal, A.O. Earth Explorer Opportunity Missions, ESA. (1998). 